\title{
Fluid Flow Analysis of a Transmission Line of Jalalabad Gas Transmission and Distribution System Limited
}

\author{
Jahan Labiba Nusrat ${ }^{1,}$, , Dey Debotosh ${ }^{1}$, Hashan Mahamudul ${ }^{2}$ \\ ${ }^{1}$ Department of Petroleum and Mining Engineering, Shahjalal University of Science and Technology, Sylhet, Bangladesh \\ ${ }^{2}$ Ecole Nationale Superieure de Geologie, University of Lorraine, Nancy, France
}

Email address:

labiba.nusrat@gmail.com (J. L. Nusrat)

\section{To cite this article:}

Jahan Labiba Nusrat, Dey Debotosh, Hashan Mahamudul. Fluid Flow Analysis of a Transmission Line of Jalalabad Gas Transmission and Distribution System Limited. International Journal of Oil, Gas and Coal Engineering. Vol. 3, No. 2, 2015, pp. 24-32.

doi: 10.11648/j.ogce.20150302.12

\begin{abstract}
In present world the prime concern of a country is energy. Bangladesh, a developing country, is also facing the challenge to meet its energy demand. For the energy, Bangladesh mainly depends on its natural gas. Bangladesh has a gas reach province in the eastern part. Gas produced in Bangladesh is mainly dry gas, but some fields are also producing condensates. Natural gas is transported by pipeline, which is the most cost efficient way. With the edge of economy, gas transmission through pipeline brings some difficulties. Before transmitting the natural gas, condensates are separated in the gas field. In spite of the separation, some condensates are formed in the pipeline while transmitting gas. This leads to pipeline blocking, corrosion, reduction of heating value. In this study the fluid flow through Khadim-Debpur-Kumargaon (KDK) pipeline is analyzed, which is a part of the pipeline network operated by Jalalabad Gas Transmission and Distribution System Limited. To analyze the fluid flow through pipeline, pressure was calculated by single phase flow equations like Weymouth, Panhandle A and panhandle B. The pressure was also calculated using software Feket (Piper) and a statistical analysis of error calculation was done. The research focuses on the following points: i) the fluid flow pressure was under designed ii) a record of liquid formation in the pipeline should be kept iii) a chromatographic test on Kumargaon station should be done for improvement of the study iv) liquid formation gives hints of two phase flow in the pipeline, which demands more investigation.
\end{abstract}

Keywords: Natural Gas, Transportation, Pipeline, Pressure Loss, Fluid Phase

\section{Introduction}

Bangladesh has been known as a prospective gas province since the discoveries of major gas fields in the east during 1960s. All the gas fields are located in the eastern part of the country [1].

Transporting natural gas through pipeline is the easiest means to transfer it from one location to further distant locations. Pipelines carrying natural gas usually buried underground and operate under higher pressure. Other means of transporting natural gas are liquefied form that is known as LNG (Liquefied Natural Gas) and hydrate form where gas is allowed to mix with water to form hydrate. Hydrate form is still under experimental stage. LNG and Hydrate requires huge capital investment and moderate operating cost. In contrary, gas pipeline needs huge initial cost but operating cost is very low [2].Bangladesh already has an established pipeline network and Khadim-Debpur-Kumargaon (KDK) pipeline is located in Sylhet District and operated by Jalalbad Gas Transmossion and Distribution System Limited (JGTDSL) (Figure.1). It mainly transports gas to northeastern part of Bangladesh. Total length of the KDK pipeline is almost $17 \mathrm{~km}$ and diameter varies from 10.02 to 11.376 inches. Most of the industries, power plant and fertilizer factory depend on this line. Any operation problems in this pipeline will severely affect the power sector and the industries. KDK line was divided into 02 (two) segments for calculation purposes.

Table 1 gives them below.

Table 1. Description of KDK line.

\begin{tabular}{llll}
\hline $\begin{array}{l}\text { No. of the } \\
\text { segment }\end{array}$ & $\begin{array}{l}\text { Name of the } \\
\text { segment }\end{array}$ & Length, Km & Diameter, inch \\
\hline 1 & $\begin{array}{l}\text { Khadim DRS- } \\
\text { Debpur DRS } \\
\text { Debpur DRS - } \\
\text { Kumargaon DRS }\end{array}$ & 5 & 11.376 \\
2 & 12 & 10.02 \\
\hline
\end{tabular}




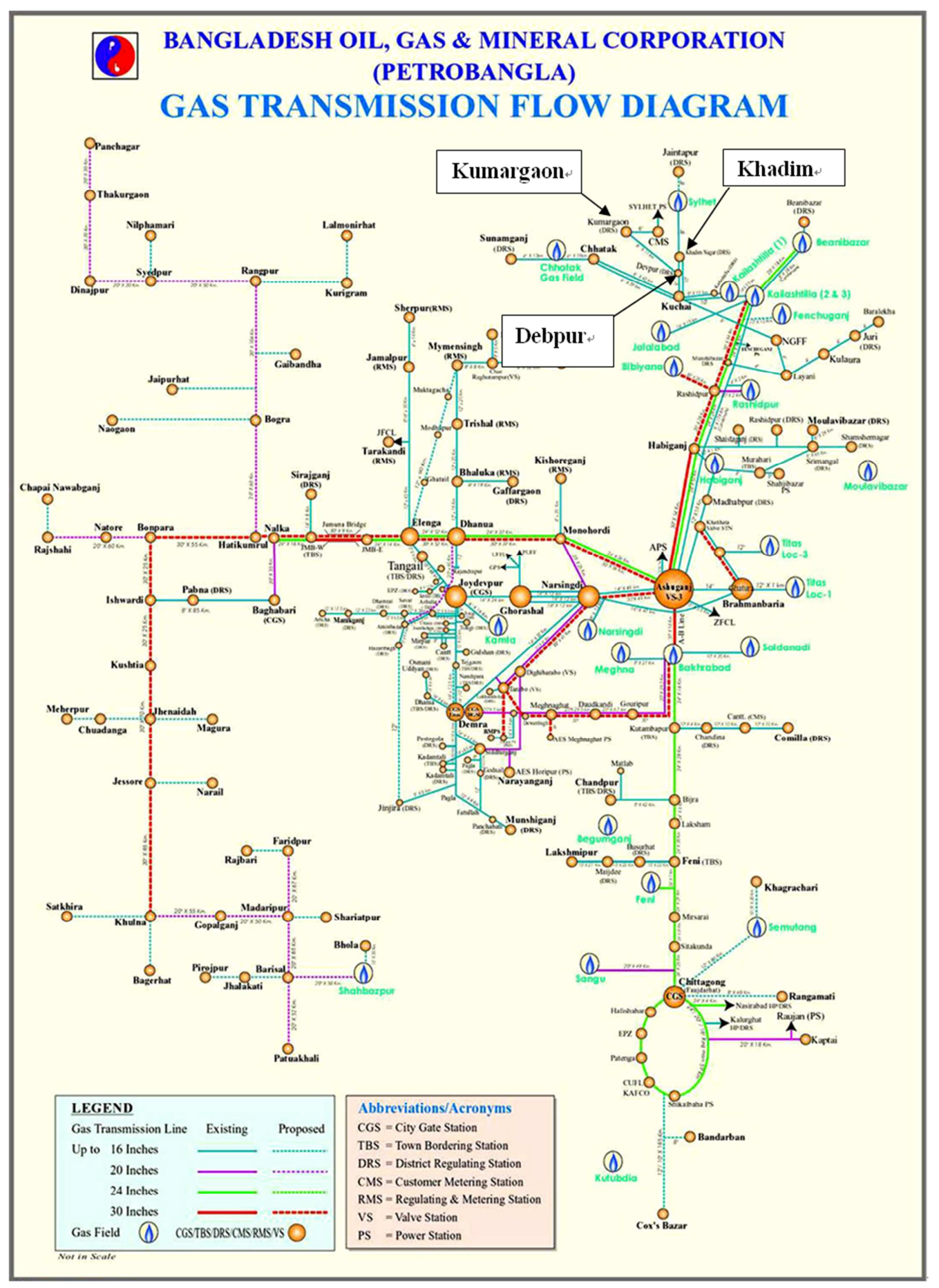

Figure 1. Gas Transmission Flow Diagram of Bangladesh (www.petrobangla.org.bd/data/flow_large.jpg).

When operating parameters i.e. flow rate, pressure and temperature changes or any operating condition change in the processing plants, liquid separate out from the gas stream because of multi- component nature of natural gas and its associated phase behavior. The separated out liquid might accumulate in the pipeline or carry over by the gas stream. Though gas is transmitted as dry gas, Jalalbad Gas Transmossion and Distribution Company Limited (JGTDCL) sometime having complains about excessive condensate in pipeline gas from her bulk customers. Sometimes they also face liquid accumulation in the pipeline; to remove it they do gas purging.

In this paper we tried to figure out a) the effect of pressure loss calculation by single phase correlations b) Build knowledge about fluid flow parameters. C) Build knowledge about problems associated with transmission of gas through pipeline. 


\section{Methodology}

Daily Transmission data and average input to the different DRS were collected from the JGTCL. This daily report contains the operation variables like pressure, temperature and gas flow rates. Using FEKET-PIPER software pressure drop was calculated. The pressure drop was also calculated by single-phase equations like Weymouth, Panhandle A and Panhandle B. Later on a statistical analysis was carried out to find the best correlation for pressure drop.

\subsection{Schematic Diagram}

Figure 2, shows the schematic view of the KDK Pipeline, where major input and output were shown only. Pipeline was assumed straight line and undulation of pipeline was ignored.

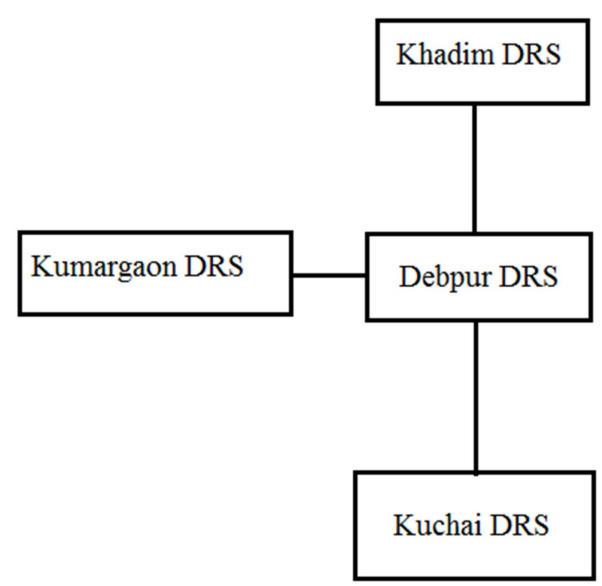

Figure 2. The Schematic Diagram of Khadim-Debpur-Kumargaon Pipeline.

\subsection{Pressure Calculations}

Engineering of long-distance transportation of natural gas by pipeline requires a knowledge of flow formulas for calculating capacity and pressure requirements. The basis for fluid flow calculations in pipes is conservation of mass, momentum and energy. Application of these principles allows the calculation of changes in pressure and temperature with distance.

There are several equations in the petroleum industry for calculating pressure in pipelines. In the early development of the natural gas transmission industry, pressures were low and the equations used for design purposes were simple and adequate. However, as pressure increased to meet higher capacity demands, equations were developed to meet the new requirements. Several equations are available that relate the gas flow rate with gas properties, pipe diameter and length, and upstream and downstream pressures. Probably the most common pipeline flow equation is the Weymouth equation, which is generally preferred for smaller-diameter lines (D 15 in. \pm ). The Panhandle equation and the Modified Panhandle equation are usually better for larger-sized transmission lines [3]. In commercial software like Fekete, Panhandle - B is used for pressure calculations. Assumptions for various pipeline flow equations are given in Table 2.
Table 2. Assumptions of Various Pipeline Flow Equations.

\begin{tabular}{|c|c|c|}
\hline $\begin{array}{l}\text { No. of } \\
\text { Pressure } \\
\text { Equations }\end{array}$ & $\begin{array}{l}\text { Name of } \\
\text { Pressure } \\
\text { Equations }\end{array}$ & Assumptions \\
\hline \multirow{7}{*}{1} & \multirow{7}{*}{ Weymouth } & No mechanical work. \\
\hline & & Isothermal Steady -State flow. \\
\hline & & Constant Gas Compressibility \\
\hline & & Factor. \\
\hline & & No undulation. \\
\hline & & Negligible kinetic energy change. \\
\hline & & $\begin{array}{l}\text { Fully turbulent flow in pipe with } \\
\text { diameters around NPS } 36 \text {. }\end{array}$ \\
\hline \multirow[b]{2}{*}{2} & \multirow[b]{2}{*}{ Panhandle A } & $\begin{array}{l}\text { Pipe diameter from NPS } 6 \text { to NPS } \\
24 \text {. }\end{array}$ \\
\hline & & $\begin{array}{l}\text { Reynolds number greater than } \\
300,000 \text { with partially turbulent } \\
\text { flow. }\end{array}$ \\
\hline 3 & Panhandle B & $\begin{array}{l}\text { Long pipelines with diameter greater } \\
\text { than NPS } 24 \text {. }\end{array}$ \\
\hline 4 & $\begin{array}{l}\text { Fekete Software } \\
\text { (Piper) }\end{array}$ & $\begin{array}{l}\text { Single-phase flow using Panhandle } \\
\mathrm{B} \text { as governing equation. }\end{array}$ \\
\hline
\end{tabular}

\subsubsection{Weymouth Equation}

The following form of Weymouth equation commonly used in industry [3]

$$
q_{h}=18.062 \frac{T_{b}}{P_{b}}\left(\frac{\left(P^{2}-P^{2}\right) D^{16 / 3}}{\gamma_{g} \bar{T} L \bar{z}}\right)^{.5}
$$

$\mathrm{q}_{\mathrm{h}}=$ gas flow rate, $\mathrm{cfh}$ at $\mathrm{pb}$ and $\mathrm{Tb}$

$\mathrm{T}_{\mathrm{b}}=$ base temperature, $\mathrm{R}$

$\mathrm{P}_{\mathrm{b}}=$ base pressure, psia

$\mathrm{P}_{1}=$ inlet pressure, psia

$\mathrm{p}_{2}=$ outlet pressure, psia

$\mathrm{D}=$ inside diameter of pipe, in.

$\Upsilon_{\mathrm{g}}=$ gas specific gravity $($ air $=1)$

$\bar{T}=$ average flowing temperature, $\mathrm{R}$

$\mathrm{L}=$ length of pipe, miles

$\bar{Z}=$ gas deviation factor at average flowing temperature and average pressure.

\subsubsection{Panhandle A Equation-Horizontal Flow}

The Panhandle A pipeline flow equation assumes that $\mathrm{f}$ varies as follows

$$
f=\frac{0.085}{N_{R e}^{0.147}}
$$

The pipeline flow equation is thus

$$
q=435.87\left[\left(\frac{T_{b}}{P_{b}}\right)^{1.07881}\left(\frac{P_{1}{ }^{2}-P_{2}{ }^{2}}{\overline{T L \bar{Z}}}\right)^{.5394}\left(\frac{1}{\gamma_{g}}\right)^{.4604} D^{2.6182}\right]
$$

Where

$\mathrm{q}$ is the gas flow rate, cfd measured at $\mathrm{T}_{\mathrm{b}}$ and $\mathrm{p}_{\mathrm{b}}$

$\mathrm{T}_{\mathrm{b}}=$ base temperature, ${ }^{\circ} \mathrm{R}$

$\mathrm{P}_{\mathrm{b}}=$ base pressure, $\mathrm{psia}$

$\mathrm{P}_{1}=$ inlet pressure, $\mathrm{psia}$

$\mathrm{p}_{2}=$ outlet pressure, psia

$\mathrm{D}=$ inside diameter of pipe, in.

$\Upsilon_{\mathrm{g}}=$ gas specific gravity $($ air $=1)$ 
$\bar{T}=$ average flowing temperature, $\mathrm{R}$

$\mathrm{L}=$ length of pipe, miles

$\bar{z}=$ gas deviation factor at average flowing temperature and average pressure

\subsubsection{Modified Panhandle (Panhandle B) Equation- Horizontal Flow}

This is probably the most widely used equation for long lines (transmission and delivery) [3]. The modified Panhandle equation assumes that $\mathrm{f}$ varies as

$$
f=\frac{0.015}{N_{R e}^{0.0392}}
$$

and results in

$$
q=737\left(\frac{T_{b}}{P_{b}}\right)^{1.02}\left(\frac{P_{1}^{2}-P_{2}^{2}}{\overline{\bar{T}} L \overline{\bar{z}} \gamma_{g}^{0.961}}\right)^{0.510} D^{2.530}
$$

\subsection{Statistical Analyses}

Any correlation that is presented in this study should be checked statistically in order to obtain a quantitative measurement about the accuracy of the prediction. Some basic statistical parameters used for correlation performance evaluation are average percentage relative error (APRE), average absolute percentage relative error (AAPRE) and standard error of estimate (SEE).

Average Percentage Relative Error (APRE) is a measure of the relative deviation of the predicted values from the experimental values in the percentage. The equation is given as follows,

$$
\text { APRE }=\left(\frac{1}{n}\right) \times \sum\left[\frac{\{(\text { Ypred }-\mathrm{Y} \exp ) \times 100\}}{\mathrm{Y} \exp }\right]
$$

The smaller the error is the more evenly distributed the positive and negative differences between predicted and experimental values.

\section{Results and Discussion}

In calculations pipeline network was simplified with considering all intakes and off takes into few major points. Effects of valves, strainer and geometry like elbow, undulation etc were ignored. As the gas flowing through the pipeline is produced from Horipur gas field, we consider the gas properties of Horipur gas field for the calculation of several physical properties of gas.

\subsection{Segment 1(Khadim DRS- Debpur DRS)}

\subsubsection{Pressure Calculation}

In pressure calculations, Reynolds's Number and all physical properties are determined in average temperature and pressure. Also, pressure was calculated by Weymouth, Panhandle A, Panhandle B and Fekete Software (Piper, using Panhandle B) for single-phase flow. All results are given in

\begin{tabular}{|c|c|c|c|c|c|}
\hline Date & Measured & Weymouth & Panhandle A & Panhandle B & Piper \\
\hline $01-02.07 .14$ & 954.7 & 1003.02 & 1010.809 & 1008.187 & 989.98 \\
\hline $02-03.07 .14$ & 944.7 & 1002.135 & 1010.538 & 1007.705 & 989.76 \\
\hline $03-04.07 .14$ & 984.7 & 1003.736 & 1011.03 & 1008.578 & 992.34 \\
\hline 04-05.07.14 & 994.7 & 1005.675 & 1011.634 & 1009.639 & 995.67 \\
\hline $05-06.07 .14$ & 994.7 & 1007.151 & 1012.1 & 1010.451 & 998.24 \\
\hline $06-07.07 .14$ & 969.7 & 1002.801 & 1010.742 & 1008.068 & 997.89 \\
\hline 07-08.07.14 & 954.7 & 1000.95 & 1010.177 & 1007.062 & 998.87 \\
\hline $09-10.07 .14$ & 914.7 & 1000.124 & 1009.927 & 1006.613 & 991.54 \\
\hline $10-11.07 .14$ & 934.7 & 1001.063 & 1010.211 & 1007.123 & 990.75 \\
\hline $11-12.07 .14$ & 960.7 & 1002.008 & 1010.499 & 1007.636 & 992.76 \\
\hline $12-13.07 .14$ & 969.7 & 1001.322 & 1010.29 & 1007.263 & 991.23 \\
\hline $13-14.07 .14$ & 944.7 & 1001.634 & 1010.385 & 1007.433 & 987.12 \\
\hline $14-15.07 .14$ & 981.7 & 1001.656 & 1010.392 & 1007.445 & 989.23 \\
\hline $15-16.07 .14$ & 954.7 & 1002.587 & 1010.676 & 1007.952 & 987.35 \\
\hline $16-17.07 .14$ & 994.7 & 1002.967 & 1010.793 & 1008.159 & 988.34 \\
\hline $18-19.07 .14$ & 949.7 & 1002.549 & 1010.665 & 1007.931 & 990.87 \\
\hline $19-20.07 .14$ & 954.7 & 1001.104 & 1010.224 & 1007.145 & 991.53 \\
\hline $20-21.07 .14$ & 991.7 & 1002.059 & 1010.515 & 1007.664 & 987.79 \\
\hline $21-22.07 .14$ & 929.7 & 1000.664 & 1010.09 & 1006.906 & 987.25 \\
\hline $22-23.07 .14$ & 934.7 & 1000.451 & 1010.026 & 1006.791 & 986.52 \\
\hline $23-24.07 .14$ & 939.7 & 1000.398 & 1010.009 & 1006.762 & 982.4 \\
\hline $24-25.07 .14$ & 929.7 & 999.9933 & 1009.887 & 1006.542 & 989.27 \\
\hline $25-26.07 .14$ & 934.7 & 1000.709 & 1010.103 & 1006.93 & 986.26 \\
\hline $26-27.07 .14$ & 954.7 & 1001.247 & 1010.267 & 1007.223 & 993.26 \\
\hline $27-28.07 .14$ & 989.7 & 1005.663 & 1011.63 & 1009.633 & 992.49 \\
\hline $28-29.07 .14$ & 999.7 & 1010.56 & 1013.209 & 1012.341 & 997.76 \\
\hline $29-30.07 .14$ & 1002.7 & 1012.687 & 1013.935 & 1013.536 & 996.27 \\
\hline $30-31.07 .14$ & 1004.7 & 1013.234 & 1014.13 & 1013.847 & 994.25 \\
\hline $31-01.08 .14$ & 984.7 & 1012.797 & 1013.974 & 1013.598 & 992.26 \\
\hline
\end{tabular}
the tables below.

Table 3. Comparison of measured and calculated pressure data for Segment 1. 


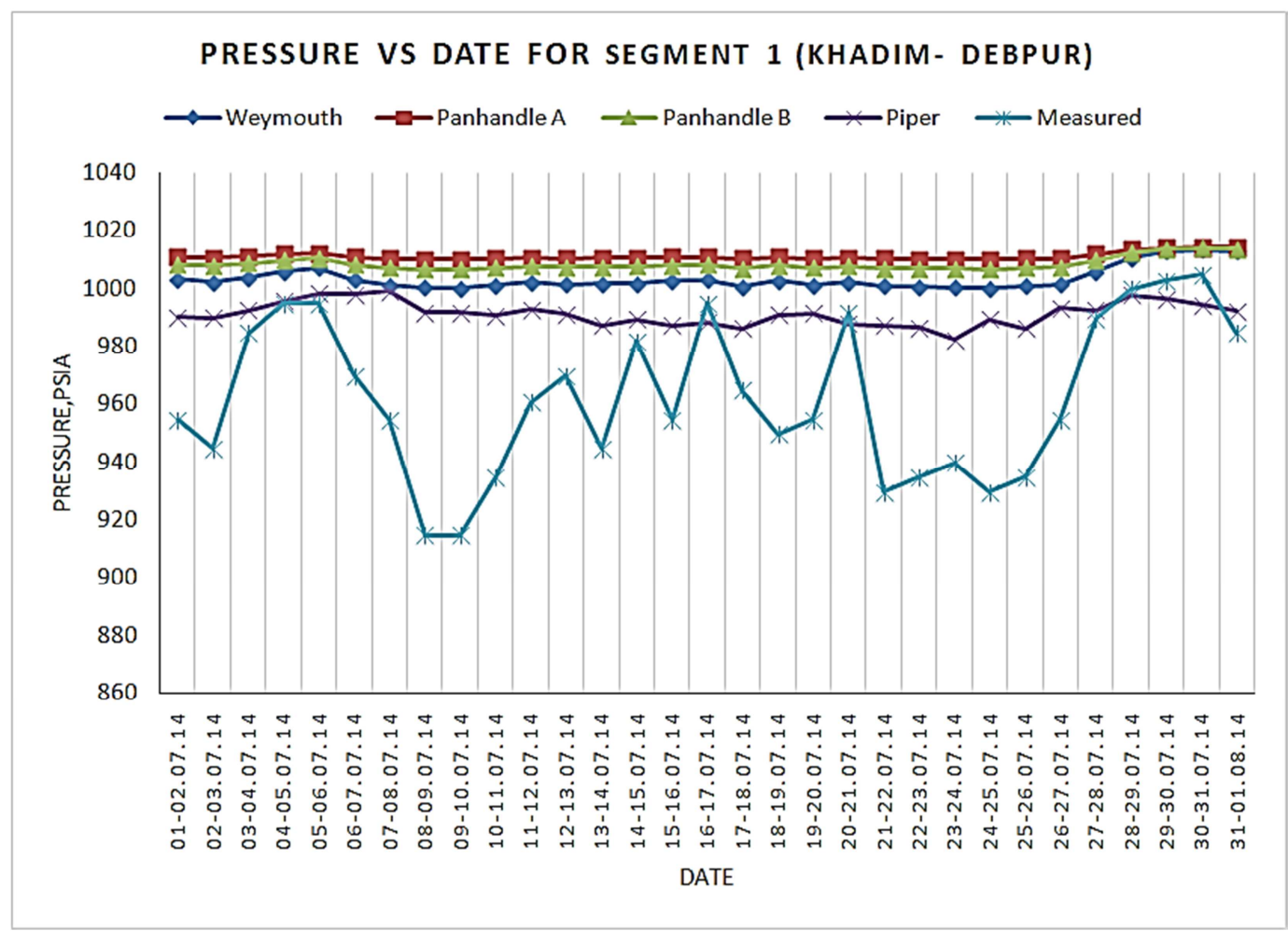

Figure 3. Pressure vs. Date for Segment 1.

\subsubsection{APRE Values for Segment 1}

APRE values for different pressure equations are given in the table below.

Table 4. Comparison of measured and calculated APRE values for Segment 1.

\begin{tabular}{|c|c|c|c|c|}
\hline Date & Weymouth & Panhandle A & Panhandle B & Piper \\
\hline $01-02.07 .14$ & 5.061253 & 5.877137 & 5.602539 & 3.6954 \\
\hline $02-03.07 .14$ & 6.079681 & 6.969155 & 6.669349 & 4.76977 \\
\hline 03-04.07.14 & 1.933169 & 2.673897 & 2.424922 & 0.77587 \\
\hline $04-05.07 .14$ & 1.103332 & 1.702407 & 1.501903 & 0.09752 \\
\hline $05-06.07 .14$ & 1.251716 & 1.749316 & 1.583477 & 0.35589 \\
\hline $06-07.07 .14$ & 3.413512 & 4.232415 & 3.956697 & 2.90708 \\
\hline $07-08.07 .14$ & 4.844493 & 5.810915 & 5.484604 & 4.62658 \\
\hline 08-09.07.14 & 9.341312 & 10.41138 & 10.04969 & 8.42462 \\
\hline $09-10.07 .14$ & 9.339018 & 10.41069 & 10.04845 & 8.40057 \\
\hline $10-11.07 .14$ & 7.099937 & 8.078638 & 7.748233 & 5.99658 \\
\hline $11-12.07 .14$ & 4.29976 & 5.183596 & 4.885631 & 3.33715 \\
\hline $12-13.07 .14$ & 3.260988 & 4.185797 & 3.873699 & 2.22027 \\
\hline $13-14.07 .14$ & 6.026674 & 6.952973 & 6.640515 & 4.49031 \\
\hline $14-15.07 .14$ & 2.032827 & 2.922637 & 2.622497 & 0.76704 \\
\hline $15-16.07 .14$ & 5.015924 & 5.863215 & 5.577836 & 3.41992 \\
\hline $16-17.07 .14$ & 0.831149 & 1.617868 & 1.353062 & -0.63939 \\
\hline $17-18.07 .14$ & 3.716428 & 4.701579 & 4.368766 & 2.2266 \\
\hline $18-19.07 .14$ & 5.564827 & 6.419343 & 6.131512 & 4.33505 \\
\hline $19-20.07 .14$ & 4.860632 & 5.815815 & 5.493368 & 3.85776 \\
\hline $20-21.07 .14$ & 1.044594 & 1.8972 & 1.609786 & -0.39427 \\
\hline $21-22.07 .14$ & 7.632984 & 8.646865 & 8.304397 & 6.19017 \\
\hline $22-23.07 .14$ & 7.03447 & 8.058789 & 7.712698 & 5.54402 \\
\hline $23-24.07 .14$ & 6.459311 & 7.482117 & 7.136513 & 4.544 \\
\hline $24-25.07 .14$ & 7.560858 & 8.625051 & 8.265278 & 6.40744 \\
\hline $25-26.07 .14$ & 7.062017 & 8.067132 & 7.727645 & 5.51621 \\
\hline $26-27.07 .14$ & 4.87561 & 5.820368 & 5.501504 & 4.03897 \\
\hline $27-28.07 .14$ & 1.612902 & 2.215832 & 2.014031 & 0.2819 \\
\hline $28-29.07 .14$ & 1.086373 & 1.351314 & 1.26445 & -0.19406 \\
\hline $29-30.07 .14$ & 0.99603 & 1.120513 & 1.080679 & -0.64127 \\
\hline $30-31.07 .14$ & 0.849438 & 0.938597 & 0.91042 & -1.04011 \\
\hline $31-01.08 .14$ & 2.853329 & 2.972886 & 2.934709 & 0.76775 \\
\hline
\end{tabular}




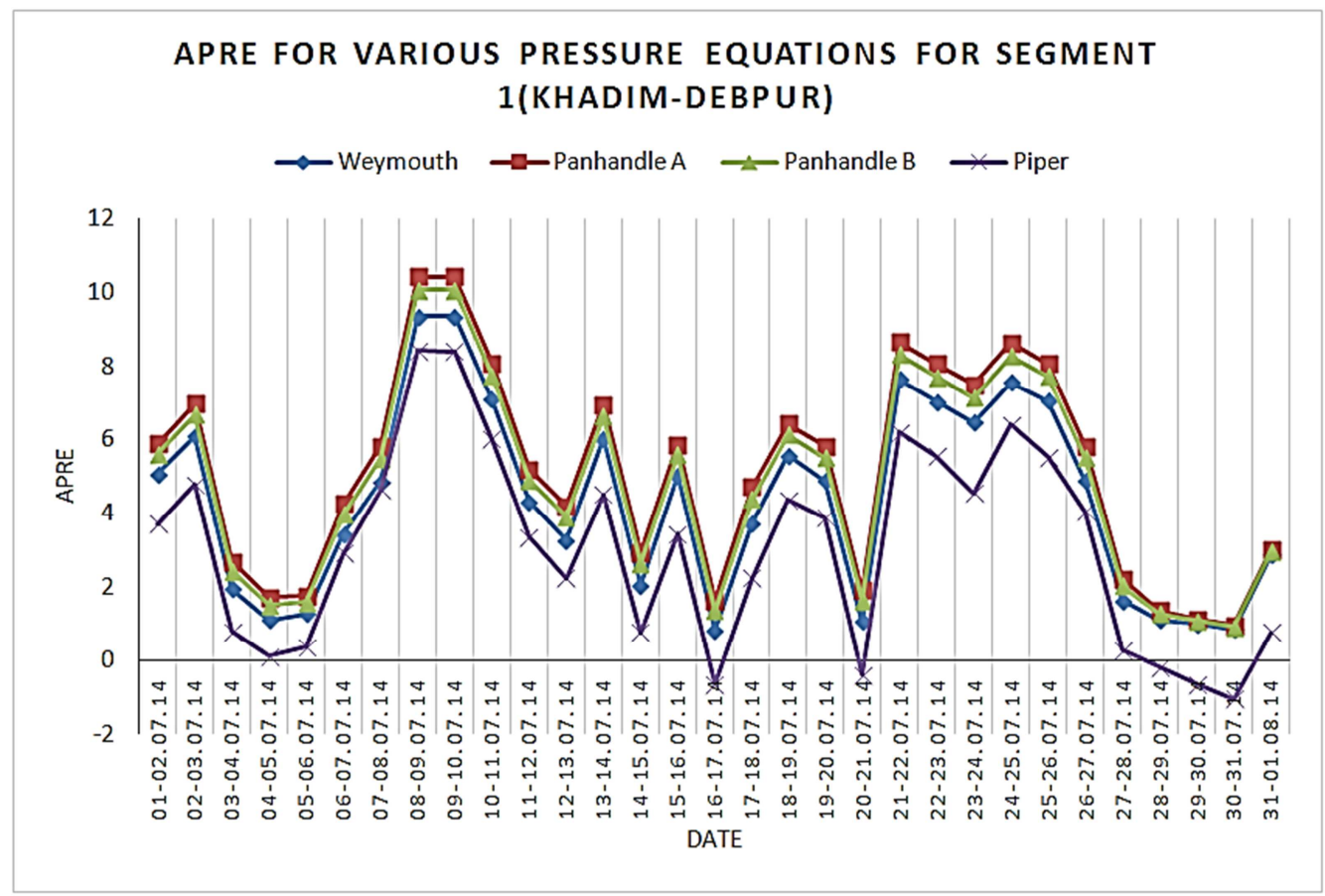

Figure 4. APRE comparison for various pressure equations for Segment 1.

\subsection{Segment 2 (Debpur DRS- Kumargaon DRS)}

\subsubsection{Pressure Calculation}

Pressure was calculated using different single phase equations and Feket (Piper) for Segment 2 (Debpur DRS- Kumargaon DRS). The comparison of different pressure values are given in the table below.

Table 5. Comparison of measured and calculated pressure data for Segment 2.

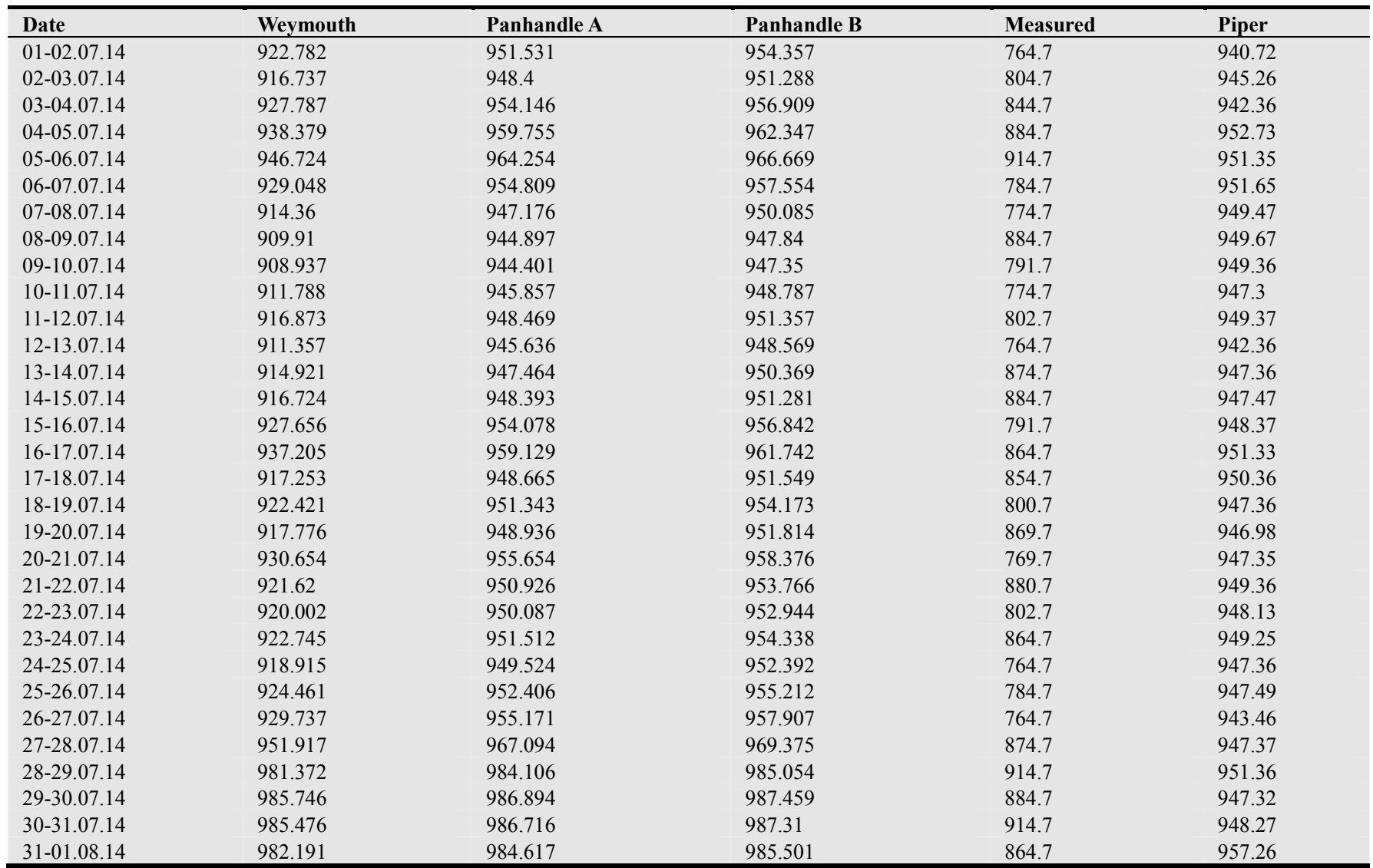




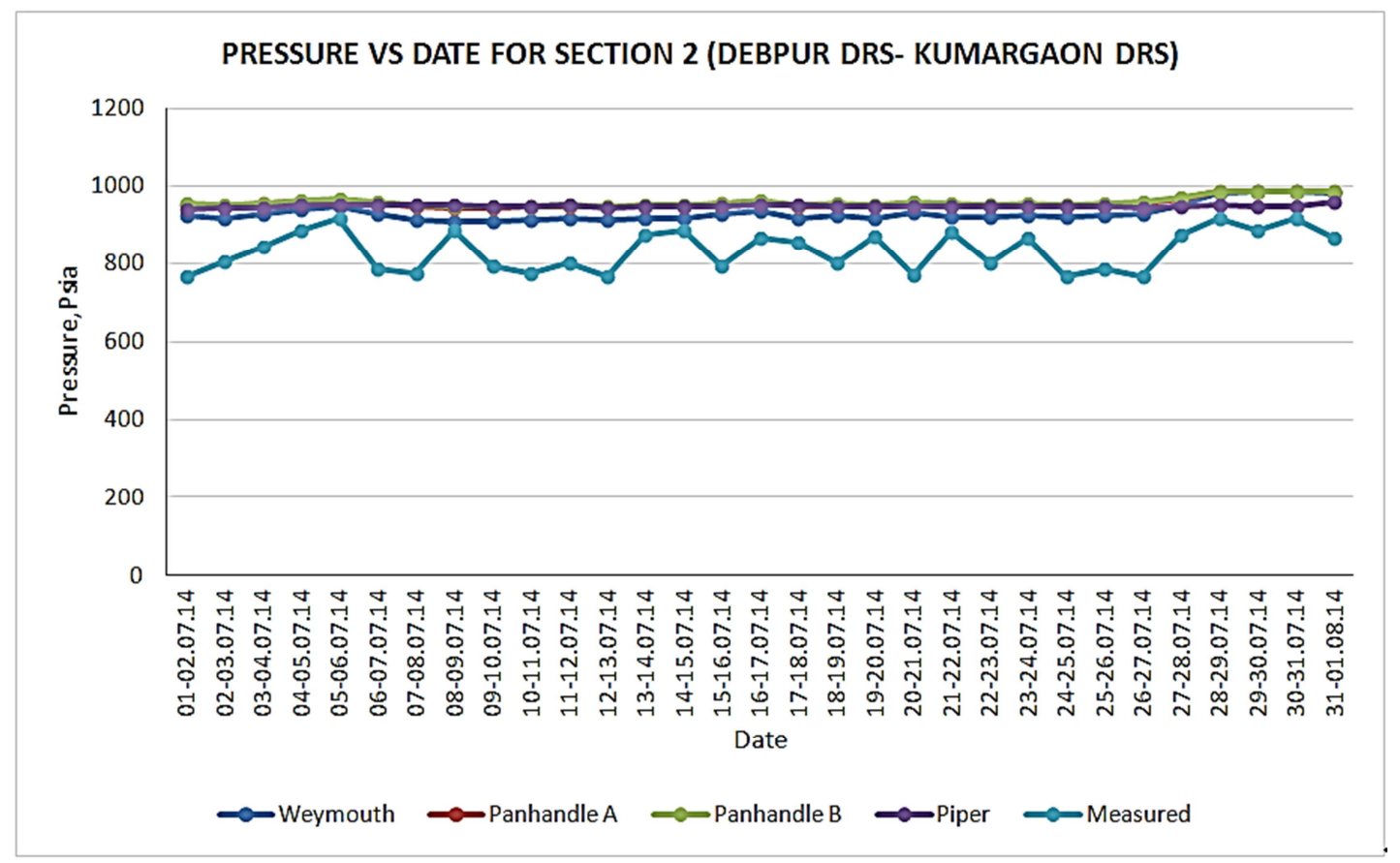

Figure 5. Pressure vs. Date for Segment.

\subsubsection{APRE Values for Segment 1}

APRE values for different pressure equations are given in the table below.

Table 6. Comparison of measured and calculated APRE values for Segment 2.

\begin{tabular}{|c|c|c|c|c|}
\hline Date & Weymouth & Panhandle A & Panhandle B & Piper \\
\hline 01-02.07.14 & 20.67244 & 24.4319 & 24.801 & 23.01818 \\
\hline $02-03.07 .14$ & 13.92289 & 17.8575 & 18.216 & 17.46738 \\
\hline 03-04.07.14 & 9.836274 & 12.9568 & 13.284 & 11.5615 \\
\hline $04-05.07 .14$ & 6.067435 & 8.48369 & 8.7767 & 7.689612 \\
\hline $05-06.07 .14$ & 3.501037 & 5.41754 & 5.6815 & 4.006778 \\
\hline 06-07.07.14 & 18.39532 & 21.6782 & 22.028 & 21.27565 \\
\hline $07-08.07 .14$ & 18.02767 & 22.2636 & 22.639 & 22.5597 \\
\hline 08-09.07.14 & 2.849557 & 6.80424 & 7.1369 & 7.343732 \\
\hline $09-10.07 .14$ & 14.80822 & 19.2877 & 19.66 & 19.91411 \\
\hline $10-11.07 .14$ & 17.69565 & 22.0933 & 22.472 & 22.27959 \\
\hline $11-12.07 .14$ & 14.22357 & 18.1599 & 18.52 & 18.27208 \\
\hline $12-13.07 .14$ & 19.17835 & 23.6611 & 24.045 & 23.23264 \\
\hline $13-14.07 .14$ & 4.598237 & 8.31876 & 8.6508 & 8.306848 \\
\hline $14-15.07 .14$ & 3.61975 & 7.19935 & 7.5259 & 7.09506 \\
\hline $15-16.07 .14$ & 17.17269 & 20.51 & 20.859 & 19.78906 \\
\hline $16-17.07 .14$ & 8.385004 & 10.9204 & 11.223 & 10.0185 \\
\hline $17-18.07 .14$ & 7.318686 & 10.994 & 11.331 & 11.19223 \\
\hline $18-19.07 .14$ & 15.20177 & 18.8139 & 19.167 & 18.31647 \\
\hline $19-20.07 .14$ & 5.527933 & 9.1107 & 9.4417 & 8.885823 \\
\hline $20-21.07 .14$ & 20.91127 & 24.1593 & 24.513 & 23.08042 \\
\hline $21-22.07 .14$ & 4.646299 & 7.97394 & 8.2963 & 7.796071 \\
\hline $22-23.07 .14$ & 14.61348 & 18.3614 & 18.717 & 18.1176 \\
\hline $23-24.07 .14$ & 6.71274 & 10.0395 & 10.366 & 9.777958 \\
\hline $24-25.07 .14$ & 20.16674 & 24.1695 & 24.545 & 23.88649 \\
\hline $25-26.07 .14$ & 17.81081 & 21.372 & 21.73 & 20.74551 \\
\hline $26-27.07 .14$ & 21.58191 & 24.9079 & 25.266 & 23.37649 \\
\hline $27-28.07 .14$ & 8.827771 & 10.5629 & 10.824 & 8.307991 \\
\hline $28-29.07 .14$ & 7.288962 & 7.58783 & 7.6915 & 4.007871 \\
\hline $29-30.07 .14$ & 11.42149 & 11.5512 & 11.615 & 7.078106 \\
\hline $30-31.07 .14$ & 7.737606 & 7.87323 & 7.9381 & 3.670056 \\
\hline $31-01.08 .14$ & 13.58744 & 13.868 & 13.97 & 10.70429 \\
\hline
\end{tabular}




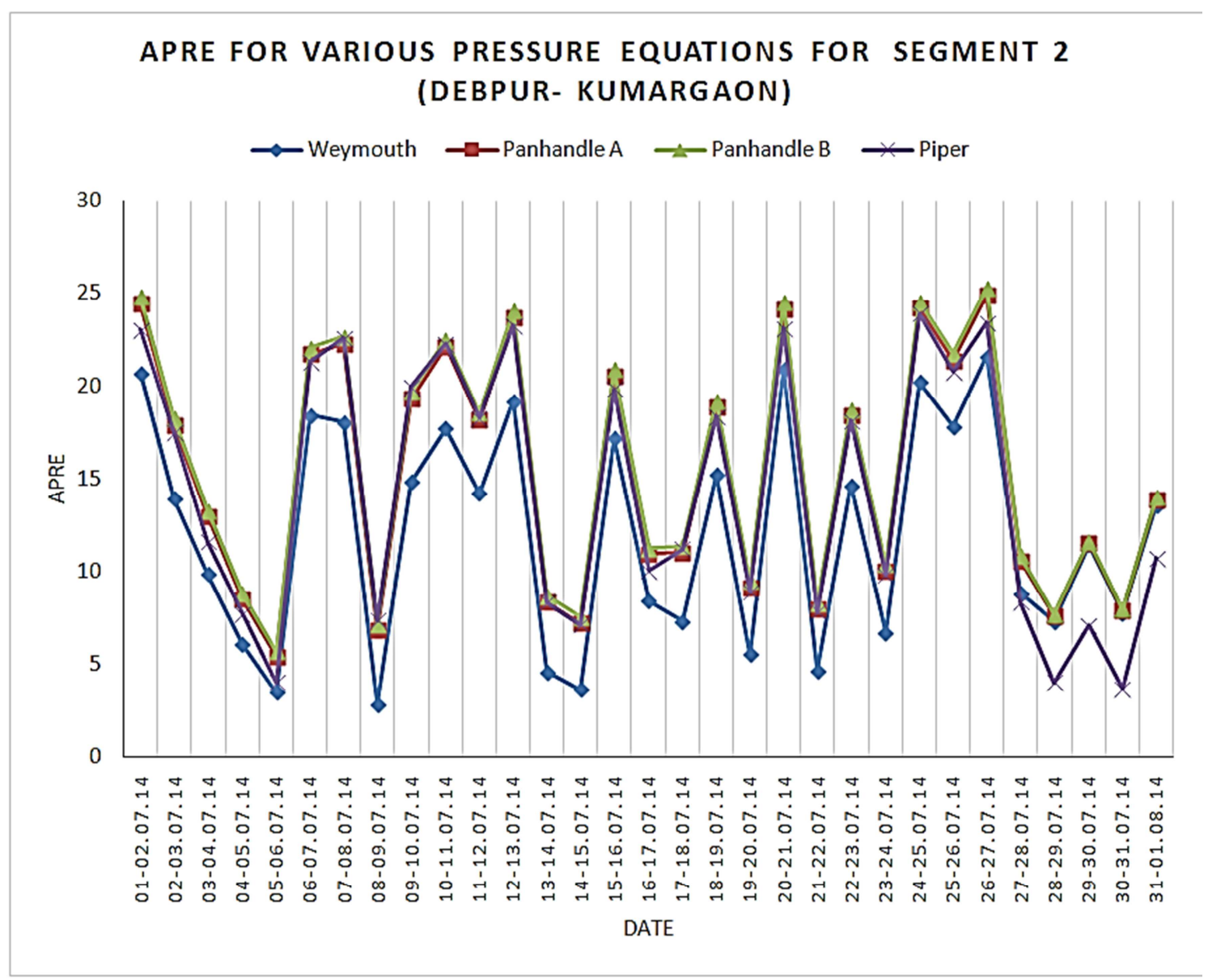

Figure 6. APRE comparison for various pressure equations for Segment 1.

Pressure calculated by Panhandle B method gave good results. As, Piper used panhandle B as a governing equation, it gave satisfactory result also. Weymouth equation is valid for pipeline diameter $<15$ inch \pm , so it follows the measured value line. Panhandle A gave unsatisfactory results.

\subsection{Problems Faced By JGTDSL}

While transmitting gas through KDK pipeline JGTDSL faces following problems: a) Liquid forms in the pipeline, which sometimes block the pipeline. b) Temperature and heating value decreases. c) There is always a volume gain at Kumargaon Station. JGTDSL takes following steps to overcome the above problems: a) They do the gas purging to clear the block. b) Before delivering the gas to their customers, gas is heated by a water bath heater at kumargaon station. c) Currently they are not taking any steps relating to this problem as their attention is on heating value.

\section{Conclusion}

\subsection{Conclusion}

The present study has led to following conclusions that are important from the authors' viewpoint. a) When pressure is calculated for single-phase flow, it is under designed. b) Statistical analysis supports this engineering problem. So, a computer generated pressure calculation may solve this problem. c) As liquids form in the pipeline during transmission, it indicates two phase flow in the pipeline, which demands further study.

\subsection{Future Recommendation}

As there are various assumptions in this work, it can be stated that improved results will come if proper information is used. In future, one can improve this work by making the following corrections. a) If physical parameters like gas and liquid flow rates, pressures, diameters are known at Kuchai point, this study will be improved by completing the network analysis properly. b) As JGTDSL does not have gas Chromatograph at Kumargaon Station, a gas sample can be collected and a gas chromatographic analysis report will improve the result. c) At Kuchai point, no pressure data is found from Daily Production Report provided by JGTDSL. So, calculated pressure cannot be compared with measured data at this point. A real pressure data can change the result.

\section{Acknowledgement}

We would like to thank Engr. Md. Shaheenur Islam, GM Operation, Jalalabad Gas Transportation \& Distribution System Limited, for his kind support and cooperation. 


\section{References}

[1] Imam Badrul. "Energy Resources of Bangladesh" $2^{\text {nd }}$ edition,2013

[2] E. Shashi Menon "Gas Pipeline Hydraulics"

[3] Ikoku Chi U. "Natural gas reservoir engineering"

[4] Ahmed Tarek "Reservoir Engineering Handbook" $2^{\text {nd }}$ edition

[5] www.sgfl.org.bd

[6] Adewumi, Michael A., Mucharam, Leksono. "Compositional Multiphase Hydrodynamic Modeling of Gas/Gas-Condensate Dispersed Flow in Gas Pipelines". SPE Production Engineering. Volume 5, Number 1. February 1990.

[7] Brill P. James and Mukherjee Hemanta. "Multiphase Flow in wells “. Monograph Volume 17 SPE Henry L. Doherty Series.

[8] Bobok Elemer. Gas conditioning and Processing, Volume 1. The basic Principles.Development in Petroleum Science 32." Fluid Mechanics for Petroleum Engineers “. Elsevier.

[9] Curtis H. Whitson, Michael L. Michelsen, The Negative Flash, Fluid Phase Equilibria, 53 (1989) 51-71.

[10] Felder M. Richard and Rousseau W. Ronald. "Elementary Principles of the Chemical Process". 2nd Edition, John Wiley \& Sons, NY.

[11] John L. Kennedy." Oil and Gas Pipeline Fundamentals". $2^{\text {nd }}$ Edition. pennWell Books.

[12] Kumar S. Contributions in Petroleum Geology and Engineering, Volume 4. "Gas Production Engineering". Gulf Publishing System. Book Division.

[13] Shoham Ovadia. " Mechanistic Modeling of gas- liquid two phase flow in pipes". The University of Tulsa. Copyright The Society of Petroleum Engineers SPE 2003.

[14] Smith J.M., Van Ness H.C. and Abbott M.M. "Introduction to Chemical Engineering Thermodynamics". $5^{\text {th }}$ Edition, The McGraw-Hill Companies, InC.

[15] Dr. A.H Younger "Natural Gas Processing Principles and , Technology - Part I .April 2004"

[16] Michael J. Economides , A. Daniel Hill , Christine EhligEconomides "Petroleum Production Systems "(2nd Edition)

[17] Ali Danesh "PVT and Phase Behaviour Of Petroleum Reservoir Fluids"

[18] William D. McCain "The Properties of Petroleum Fluids" (2nd edition)

[19] www.petrobangla.org.bd 